For $\phi=0, r=a$, corresponding to the point A.

For $\phi=180^{\circ}, r=a \sec 60^{\circ}=2 a$, corresponding to the point $\mathrm{I}$.

For $\phi=270^{\circ}, r=\infty$, and the curve becomes asymptotic with the line $d m$, now tangent at $\mathrm{A}^{\prime}$ to the arc $\mathrm{A} d \mathrm{~A}^{\prime}$.

The curve, extended beyond $\mathrm{A}$, will have two symmetrical branches with reference to the line AI.

The portion shown in Fig. I need alone be considered.

This curve possesses the following property :-

If a line is drawn making any angle, $\mathrm{PCK}$, with $\mathrm{CP}$, and from its intersection with the curve, at $m$, as a centre, an arc be struck with a radius equal to $\mathrm{cm}$, its intersection with the arc described with radius $\mathrm{Cl}$ will determine a point $\mathrm{C}$, the line from which to the centre $\mathrm{C}$ will trisect the angle $\mathrm{ACK}$.

To Prof. John Peirce, of Proviaence, the suggested use of the curve is due.

$$
\text { A. H. Russell, }
$$

Providence, R.I., April 13, 1889.

\section{THE ACTION OF THE NERVES OF THE BATRACHIAN HEART IN RELATION TO TEMPERATURE AND ENDOCARDIAC PRESSURE.}

\section{(Preliminary Note.)}

THIS work, which has been carried on during the past four or five months, has been chiefly concerned with the influence of temperature on the action of the sympathetic and the vagus, and only incidentally with the effect of endocardiac pressure. A re-investigation of the heat standstill of the heart has also been connected with the work. In most of the experiments tracings of the auricular and ventricular movements were taken simultaneously, and these were supplemented by a series of electrical observations.

Omitting details, the chief results are as follows. The term "vagus" is here used in its anatomical sense to denote the mixed vago-sympathetic trunk.

(I) Both the vagus and the sympathetic have their activity diminished as the temperature is lowered and increased as the temperature rises, whether changes in the rhythm or in the amplitude of the beats be taken as the test of activity. The sympathetic curve, however, falls more steeply with falling temperature than does the vagus curve, so that the vagus is generally still active $w$ ith a temperature at which the sympathetic has ceased to react.

The secondary augmentor effects of vagus stimulation are extremely well marked at the higher temperatures, and become less conspicuous as the temperature is lowered. Not only are both nerves active on the very threshold of the heat standstill, but during the actual standstill, when it has not been obtained at too high a temperature, stimulation of the sympathetic may rouse the beart to vigorous contraction.

(2) An increase of endocardiac pressure sufficient to abolish the inhibitory action of the vagus leaves the sympathetic still active, and the primary augmentation which, under these conditions, has been seen as a result of vagus stimulation, may be attributed to the sympathetic fibres in the mixed nerve.

When a high pressure is suddenly reduced, standstill of the heart may occur, and this can be removed by stimulation of the sympathetic.

(3) Heat standstill of the heart, when there is no constant stiusulus acting, such as a high endocardiac pressure, is always diastolic, and can never be described as "heat tetanus."

(4) Electrical effects, analogous to those described by Gaskell in the quiescent auricle of the tortoise on stimulation of the vagus, and in the toad's ventricle on stimulation of the sympathetic, have been looked for in vain in the heart of the frog and toad during heat standstill and the standstill caused by sudden relief of a high endocardiac pressure. The effects observed were always related to coincident or consequent mechanical changes.

So far as the sympathetic is concerned, I do not know of any previous work on the subject of this note; nor has the influence of temperature on the vagus been before studied by a suitable graphic method, but only to a small extent in any way ard by methods yielding very imperfect information.

New Museums, Cambridge.

G. N. Stewart,

\section{UNIVERSITY AND EDUCATIONAL INTELLIGENCE.}

CAMBRIDGE.-An examination for Minor Scholarships in certain branches of Law and Natural Science will be held at Downing College on Wednesday, July 8 , and subsequent days. Candidates for Minor Scholarships in Natural Science must be under the age of nineteen at the time of commencement of the examination, and must send a certificate of birth with their other papers. There is no such limit of age for candidates in Law. Further information will be furnished by the Rev. J. C. Saunders, Tutor of the College.

\section{SCIENTIFIC SERIALS.}

THE American Meteorological Fournal for February con. tains :-An account of a Iecture on the State Weather Service, delivered by Prof. F. E. Nipher at the request of the Board of Agriculture of Missouri. These services aim at weather predictions for the use of agriculturists and others, and the forecasts are of a more local character than can be attempted by the Central Office. The general use of the telephone is recommended for the purpose.-Wind-pressures and the measurement of wind velocities, by Prof. C. F. Marvin. This paper recapitulates the experiments which have been carried on in the United States, concurrently with others in this country and elsewhere, to de. termine more accurately than was at first done the constants of the Robinson cup-anemometer. The instrument used was the small pattern adopted by the Signal Service, the cups of which are 4 inches in diameter, and the arms 6.72 inches long, and for this form of anemometer the equation

$$
\log \mathrm{V}=0.509+0.9012 v \log v
$$

is recommended to be used instead of Dr. Robinson's original formula $\mathrm{V}=3 v$, which is commonly applied to all cup anemo. meters, regardless of size of cup and length of arm. An account is also given of some experiments carried out at the summit of Mount Washington, with a view to determining the wind. pressure upon large plates, and comparing it with the wind velocity recorded by the cup-anemometer. The writer finds that, with ordinary barometric pressures, the wind-pressure can be satisfactorily obtained from the wind velocity by the following formula :-

$$
\mathrm{P}=0.0040 \mathrm{~V}^{2} \mathrm{~S},
$$

where $\mathrm{V}$ is the wind velocity in miles per hour, $\mathrm{P}$ is the pressure in pounds per square foot, and $S$ is the area of the plate.Meteorological observations taken in four balloon voyages, by W. H. Hammon. The ascents were made in January, March, and April, 1885, by direction of the Chief Signal Officer. The Report contains full descriptions of the instruments and detailed observations during the ascents, which were made during conditions of the atmosphere that were considered likely to elucidate certain points. The ascents were only of slight elevation, and the observations are to be considered only as contributions to the special weather of the respective dates, and not as bearing particularly upon the questions involved in the general circulation of the air.

\section{SOCIETIES AND ACADEMIES. \\ LONDON.}

Physical Society, March 20. --Prof. W. E. Ayrton, F.R.S., President, in the chair.-Prof. S. U. Pickering, F.R.S., read a paper on the theory of dissociation into ions, and its con. sequences. According to this theory electrolytes are entirely dissociated into their ions in weak solutions. This dissociation was held by Arrhenius to absorb heat, and although heat is evolved by the dissolution of hydrochloric acid, \&c., it is not maintained that dissolution evolves heat, but that the heat absorbed by the decomposition of the molecule into its atoms is more than counterbalanced by the heat supposed to be evolved by the combination of the atoms with their electric charges. These actions the author considered improbable, and thought that before being accepted, the theory must give satisfactory answers to the following questions: How can matter combine with an affection of matter to produce heat? Whence do the electric charges originate? Why does not the opposite electri-

NO. I I I 9 , VOL. 4.37 